\title{
Loggerhead turtles dive in response to airgun sound exposure
}

\author{
Stacy L. DeRuiter ${ }^{1,3, *}$, Kamel Larbi Doukara ${ }^{2}$ \\ ${ }^{1}$ Ifremer Centre de Brest, Service Acoustique et Sismique, BP 70, 29280 Plouzané, France \\ ${ }^{2}$ University of Oran Es-Senia, Laboratoire Réseau de Surveillance Environnementale, BP 1524, \\ El M'Naouer 31000, Oran, Algeria \\ ${ }^{3}$ Present address: Biology Department, Woods Hole Oceanographic Institution, Woods Hole, Massachusetts 02543, USA
}

\begin{abstract}
Seismic airgun arrays are among the most powerful sound sources used at sea, and they have the potential to disrupt the behavior of marine life. Little information is available on marine turtle responses to airgun sounds, and few regulations mandate specific actions to protect turtles from potential impacts of airgun exploration. As part of the French-Algerian project SPIRAL (Sismique Profonde et Investigation Régionale du Nord de l'Algérie) in September and October 2009, visual observations of 164 loggerhead turtles Caretta caretta were conducted during a seismic survey in the Mediterranean Sea off Algeria. The turtles were part of a large aggregation, basking at the surface in calm seas. All sightings occurred during airgun operations, in which shots were fired every $19.4 \mathrm{~s}$ (array source level $252 \mathrm{~dB}$ re $1 \mu \mathrm{Pa}$ [peak]). Recordings from 3 hydrophones allowed estimation of near-surface airgun sound levels. Of 86 turtles visually tracked until their passage $>100 \mathrm{~m}$ behind the array, 49 (57\%) dove at or before their closest point of approach to the airguns. At least 6 dove immediately following an airgun shot, often showing a startle response. Binomial regression indicated that turtle dive probability decreased with increasing distance from the airgun array. The observed diving behavior may be interpreted as an avoidance response to airguns.
\end{abstract}

KEY WORDS: Loggerhead $\cdot$ Sea turtle $\cdot$ Caretta caretta $\cdot$ Airgun $\cdot$ Seismic $\cdot$ Noise $\cdot$ Dive behavior

\section{INTRODUCTION}

Airgun arrays are powerful sources of low-frequency impulsive sounds, used at sea for geophysical research and fossil fuel prospecting. Their operation may pose risks to marine life, because high-level exposure to impulsive sound pulses can injure animals including marine mammals, fish, and turtles, for example causing temporary or permanent damage to the auditory system (DeRuiter 2010). Exposure to anthropogenic sounds like airguns can also cause animals to alter their movements and behavior, and may subject them to stress (DeRuiter 2010). These potential risks have led many countries to impose regulations on the operation of airguns (Castellote 2007, Weir \& Dolman 2007, Compton et al. 2008). The reg- ulations are designed to minimize the potential effects of airguns on marine animals, although they generally focus specifically on marine mammals. Despite some evidence that animals respond behaviorally to airguns (Miller et al. 2009, DeRuiter 2010), the significance of these responses and the conditions in which they occur are not well understood.

Sea turtles face serious conservation challenges, with 6 of the 7 species critically endangered, endangered, or vulnerable (IUCN 2011). It is therefore important to understand whether sound sources like airguns provoke behavior changes that compromise their energy budgets, exclude them from important habitat, or increase their stress levels. Although turtles do not have particularly sensitive auditory systems, their ranges of best hearing seem to overlap 
with the low-frequency band in which airguns operate. Airgun arrays generally have peak frequencies $<200 \mathrm{~Hz}$ (Pacault \& Lurton 2010). Turtle audition is fairly poorly studied to date, but existing data suggest that they hear best between about $100 \mathrm{~Hz}$ and $1 \mathrm{kHz}$, and should thus be able detect low-frequency, highamplitude pulses from airgun arrays (Ridgway et al. 1969, Bartol et al. 1999, Streeter \& Floyd 1999, Moein Bartol \& Musick 2003, Ketten \& Bartol 2005). Given the current lack of comprehensive data on turtle hearing sensitivity, it is difficult to predict the sound exposure levels that would be required to cause them temporary or permanent hearing loss. The effects of such hearing loss on fitness are even more challenging to predict, since turtles are not known to rely heavily on sound to communicate or sense their environment. However, hearing damage is not the only way airguns could affect turtles. Turtles could also respond to airgun pulses by changing their behavior. Such changes could affect turtle fitness by reducing the time and energy available for feeding, mating, or other key activities, or by increasing the amount of time spent in suboptimal habitat (such as areas where predators are more abundant or prey less abundant).

Currently, behavioral responses of marine turtles to airgun array sounds are not well understood. Studies of captive turtles exposed to sound from individual airguns suggest that they may show startle or avoidance responses to airguns (O'Hara \& Wilcox 1990, McCauley et al. 2000, Moein Bartol \& Musick 2003). Observations of turtle responses to at-sea airgun array operations have been unable to conclusively document or rule out behavioral responses of turtles, because analysis was complicated by small

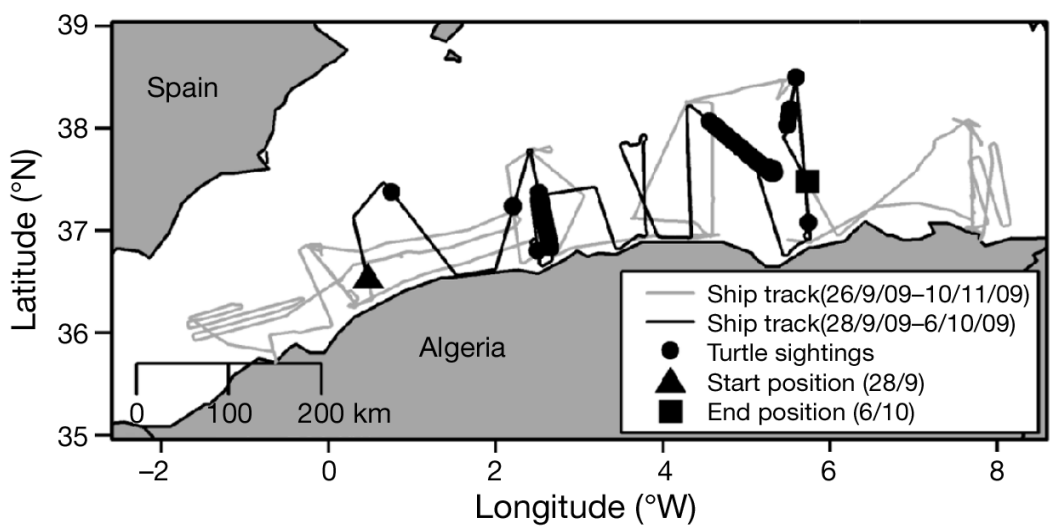

Fig. 1. Ship's track and turtle sightings. Grey trace shows the track of the RV 'Atalante' for the entire SPIRAL cruise (26 September to 10 November 2009). Black trace shows the ship's track during the days when turtles were sighted, from 28 September to 6 October 2009 (the black triangle marks the first ship position on 28 September; black square, the last ship position on 6 October). Black circles mark the locations along the track at which turtles were sighted sample size, variability of sighting rates with sea state, and confounding responses by turtles to the source vessel or other visual stimuli (de Gurjão et al. 2005, Parente et al. 2006, Weir 2007).

The current study presents an analysis of visual observations of loggerhead turtles Caretta caretta during airgun array operations in Algerian waters. We describe turtle behavioral responses to airgun array transmissions, assessing the relationship between dive occurrence, range to the airgun sound source, and airgun exposure level.

\section{MATERIALS AND METHODS}

\section{Visual observations of turtles}

At-sea visual observations of marine mammals and turtles were conducted between 26 September and 8 October 2009 during a seismic survey in the Mediterranean Sea off Algeria, as part of the FrenchAlgerian geophysical research and seafloor mapping project SPIRAL (Sismique Profonde et Investigation Régionale du Nord de l'Algérie) aboard the RV 'Atalante'. The project continued through 10 November 2009, but airgun activity was infrequent, the authors of the present study were no longer on board, and the observers on board after 9 October did not record any turtle sightings. Fig. 1 shows a map of the study area and the ship's track line. During the survey, the RV 'Atalante' traveled at a speed of 5 knots, towing a 13-gun airgun array with a total volume of $0.040 \mathrm{~m}^{-3}$ and a nominal (modeled) source level of $252 \mathrm{~dB}$ re $1 \mu \mathrm{Pa}$ at $1 \mathrm{~m}$ (peak). The array tow depth was $11.5 \mathrm{~m}$ at the center of the array. Although there are no local or regional regulations related to airgun operations in Algeria, self-imposed Ifremer guidelines required the presence of marine mammal observers (MMOs); based on observer sightings, airgun operations were suspended if any marine mammal was sighted within $500 \mathrm{~m}$ of the array, and no airgun operations commenced unless marine mammals had not been sighted within $1000 \mathrm{~m}$ of the array for at least $30 \mathrm{~min}$. At initiation of shooting, a ramp-up procedure was followed, in which the number of airguns firing was gradually increased over a $30 \mathrm{~min}$ period. During both ramp-up and full-power operations, the array was fired every $19.4 \mathrm{~s}$. 
All visual observations analyzed in the present study were collected during active airgun operations by MMO (the authors); no turtles were sighted during ramp-up or during periods when the airguns were not operating. During daylight hours, at least 1 observer was stationed on the flying bridge (eye height $13.5 \mathrm{~m}$ above the sea surface) or, in poor weather, on the bridge (eye height $12.5 \mathrm{~m}$ ) of the RV 'Atalante'. Monitoring $360^{\circ}$ around the vessel is possible from both platforms. When possible in conjunction with marine mammal observations, observers also monitored the seas in all directions for turtles, using the naked eye or Fujinon $7 \times 50$ handheld binoculars (Fujifilm). Observers recorded the time of each sighting and the position of each sighted turtle, including angle to the sighting (using an angle board and taking the ship's heading as $0^{\circ}$ ) and radial distance to the turtle (in binocular reticles or, for turtles within about $150 \mathrm{~m}$ of the ship, estimated in meters). When possible, multiple positions were recorded for each animal, photographs were taken, and further data on turtle behavior were noted. Behavior categories included basking (here defined as floating motionless and drifting at the water's surface, often with a dry shell) and swimming underwater; other events such as agitating flippers, raising head, and splashing were also noted. Occurrence of dives was recorded, including position at time of dive and swim direction, as possible. Data on environmental conditions, including sea state, wind speed and direction, swell, water depth, visibility, and ship speed were also recorded every half hour.

\section{Processing and statistical analysis of sighting data}

We converted the sighting data to positions relative to the observers (azimuth angle and range in meters) using established reticle-distance conversion factors (Lerczak \& Hobbs 1998, Kinzey \& Gerrodette 2001). These positions were then converted to positions relative to the center of the array, using standard trigonometry and observer-array geometry (the center of the array was located 94.3 m directly astern of the observer station). A track was estimated for each turtle. For turtles sighted more than once ( $\mathrm{n}=40$ ), we fit a straight line to the observed positions to establish the track using linear least squares. For turtles sighted only once, the estimated tracks were straight lines parallel to the course of the ship (see 'Results' for justification of this approximation). We used the tracks to calculate the minimum horizontal distance between each turtle and the center of the array along the turtle's track line (even if the turtle dove before passing that close to the array). This distance metric was chosen, rather than distance from the array at the time of the dive, because it can be quantified for both diving and non-diving turtles, thus allowing assessment of the probability of diving as a function of range from the array. Turtles whose track lines were equidistant from the array likely received comparable sound exposures on average, at least as long as they remained at the surface, so the chosen distance metric is an acceptable proxy for exposure. To assess the relationship between turtle dive probability and this minimum turtle-array distance, we carried out a binomial regression (with the log link function) in R (www.R-project.org). Previous work has documented diving by marine turtles in response to the close proximity of vessels or other surface objects (Weir 2007). Because control data (collected when airguns were not firing) was not available for this analysis, it is difficult to objectively determine whether turtles diving close to the ship did so because of the sound exposure or because of vessel presence. To address this issue, we chose to include in the regression only data from turtles never sighted at positions within $20^{\circ}$ of the ship's heading. Since turtle tracklines were primarily parallel to the ship, this requirement effectively excluded all turtles that came close to the ship (including the 3 individuals observed to startle and dive in response to the bow of the boat). We also carried out a separate, analogous regression analysis including only the turtles sighted within $20^{\circ}$ of the ship's heading to try to assess the relationship of dive probability and proximity to the ship.

\section{Collection and processing of acoustic data}

Airgun sounds were recorded on an array of 3 broadband hydrophones: 2 ITC 8095 hydrophones (average measured sensitivity: $188 \mathrm{~dB}$ re $1 \mathrm{~V} / \mu \mathrm{Pa}$ for frequencies $<5 \mathrm{kHz}$; ITC) and 1 Reson TC 4014 (nominal broadband sensitivity: $186 \mathrm{~dB}$ re $1 \mathrm{~V} / \mu \mathrm{Pa}$; Reson). The ITC hydrophones were deployed through an instrument well on the stern deck of the seismic vessel; they were fixed securely on a custombuilt polyethylene plate. The Reson hydrophone was permanently installed on the sonar-transducer gondola nearer the bow of the vessel. Both ITC hydrophones were located $72 \mathrm{~m}$ from the center of the airgun array, while the Reson hydrophone was $94 \mathrm{~m}$ from the array. All 3 hydrophones were at $6 \mathrm{~m}$ depth below the sea surface. 
After application of an anti-aliasing filter at $100 \mathrm{kHz}$ and 20 or $32 \mathrm{~dB}$ amplification using RAP amplifiers (Orca), hydrophone signals were digitized at a sampling rate of $192 \mathrm{kHz}$ using an NI PCI 6731 data acquisition card (National Instruments) and, finally, recorded on a computer hard drive via Pamguard software (www.pamguard.org).

The times of 156 recorded airgun arrivals were determined via visual scans of spectrograms. To determine airgun levels, we calculated the peak received level of each arrival using custom scripts in Matlatb (The MathWorks). Briefly, the program imported a $4 \mathrm{~s}$ audio clip centered on each marked arrival time, applied a 4-pole low-pass Butterworth filter at $250 \mathrm{~Hz}$, and determined the maximum peak sound pressure level in the clip. The signal-to-noise ratio (SNR) of each airgun pulse was also computed to verify that SNR was always at least $10 \mathrm{~dB}$, ensuring that low-frequency flow noise and engine noise did not inflate the calculated received levels. The resulting received levels were compared with those predicted based on a simple spherical spreading approximation of transmission loss (according to which received level declines by $6 \mathrm{~dB}$ per doubling of range) (Lurton \& Leviandier 2010). All modeling assumed far-field sound propagation, neglecting near-field effects, since the near field extends less than about $20 \mathrm{~m}$ from the source for the large, lowfrequency airgun array considered here (Le Gall et

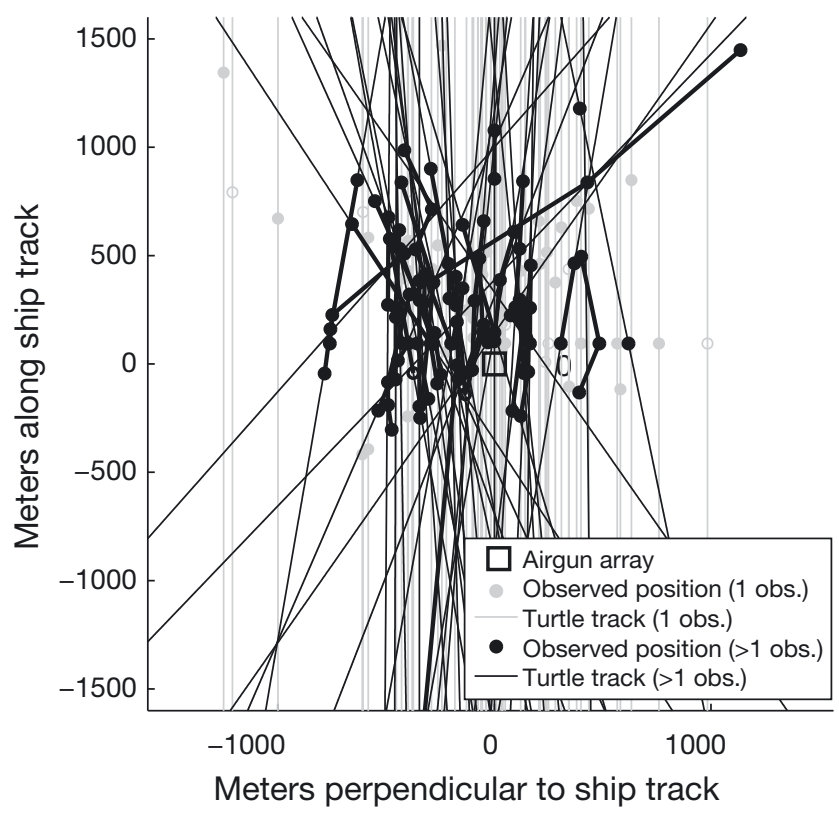

Fig. 2. Turtle positions relative to the center of the airgun array. Predicted turtle tracks were determined via straight-line fits to the data (with tracks of turtles sighted only once assumed to be parallel to the ship's track). Obs.: observation (s) al. 2010). Sound source level is 1 input to the spherical spreading model, but because airgun arrays are directional sound sources, using the on-axis source level would not give accurate results. The main beam of sound produced by an airgun array is directed toward the sea floor, and the nominal source level of a given array is measured along the axis of that beam (Pacault \& Lurton 2010). Source levels are thus lower at shallower launch angles, such as the nearhorizontal angle between the array and the hullmounted hydrophones. A simple model that takes into account airgun volume and airgun array geometry (DeRuiter et al. 2006) was used to predict off-axis airgun source levels in the direction of the hydrophones and in the direction of a turtle at the surface $130 \mathrm{~m}$ from the array (the average range at which turtles were observed to dive). The spherical spreading law was then applied to predict received levels at the 3 hull-mounted hydrophones. Comparison of the hydrophone data and the model predictions served to validate the model, which was then applied to produce rough estimates of the near-surface received levels to which turtles were exposed during the present study.

\section{RESULTS}

Over $13 \mathrm{~d}$ of observations between 26 September and 8 October, observers stood watch for $149.55 \mathrm{~h}$. Airguns were in operation at full power for $147.52 \mathrm{~h}$, in ramp-up twice for a total of $1 \mathrm{~h}$ and in shut-down once (due to marine mammals sighted near the array) for $1.03 \mathrm{~h}$. Between 28 September and 6 October, during a period of exceptionally calm seas and low winds (Beaufort 0 to 1), 164 turtles were sighted (Fig. 1). Ranges to initial sighting locations varied from 10s of meters to nearly $2 \mathrm{~km}$, and most turtle tracklines were parallel to that of the ship; the median absolute value of the slope of multiply-sighted turtle tracks was $0.14 \mathrm{~m}$ perpendicular to the track per meter along the track, with no apparent port/starboard bias (Fig. 2). This result is consistent with the observation that $98 \%$ of the turtles were basking motionless at the surface when initially sighted: in calm seas, the motion of a drifting turtle relative to a ship traveling at 5 knots will be predominantly parallel to the ship's track, and toward the stern. Because most of the tracks that incorporated data from multiple sightings were parallel to the ship's track, we were confident that little error was introduced by our assumption that turtles sighted only once also traveled along tracks parallel to that of the ship. 


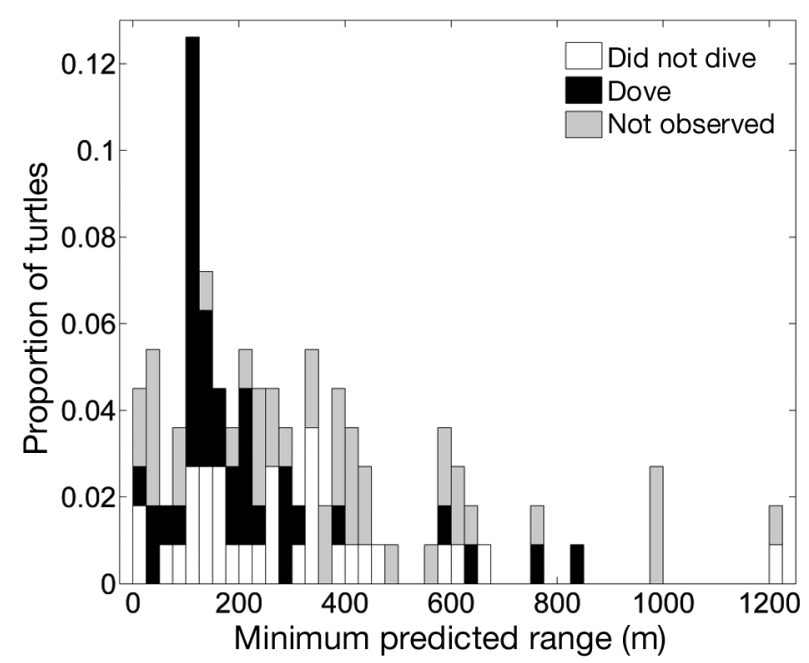

Fig. 3. Stacked histogram of turtle diving behavior $(n=164)$ as a function of minimum range from the center of the air gun array, along the predicted turtle trackline

Although some turtles were too distant to definitively identify to species (33 turtles at ranges $>500 \mathrm{~m}$ ), all were hard-shelled sea turtles. All 131 turtles sighted at close range were identified as loggerheads Caretta caretta, a determination that was later confirmed based on photographs of 12 individuals taken in the field. We presume that the unidentified turtles were probably also loggerheads, based on the fact that all identified turtles were loggerheads. The turtles were estimated to be about 0.3 to $1 \mathrm{~m}$ in carapace length. Some turtles were sighted individually (that is, there was only 1 turtle in view at the time the individual was seen), but most were part of large clusters, with several hundreds of between animals.

The initial behavior of all turtles was basking, except for 3 individuals sighted swimming underwater. Subsequently, some raised their heads (6), agitated their flippers (7), produced air bubbles around their heads (2), or dove. Of the 86 turtles whose dive behavior was observed (they dove before passing behind the airgun array, or were in view at the surface until they had passed well behind the airgun array), $49(57 \%)$ dove and 37 (43\%) did not (Fig. 3). The median range from the center of the airgun array at the time of diving was $130 \mathrm{~m}$ (range 50 to $839 \mathrm{~m}$ ). At least 6 of the turtles that dove did so immediately following an airgun shot, and their dives were accompanied by what appeared to be a startle response (sudden raising of the head and splashing of flippers, several times accompanied by blowing bubbles from the beak and nostrils, culminating in a dive after no more than $5 \mathrm{~s}$ ). Because the relative timing of turtle dives and airgun shots was not recorded for all diving tur-

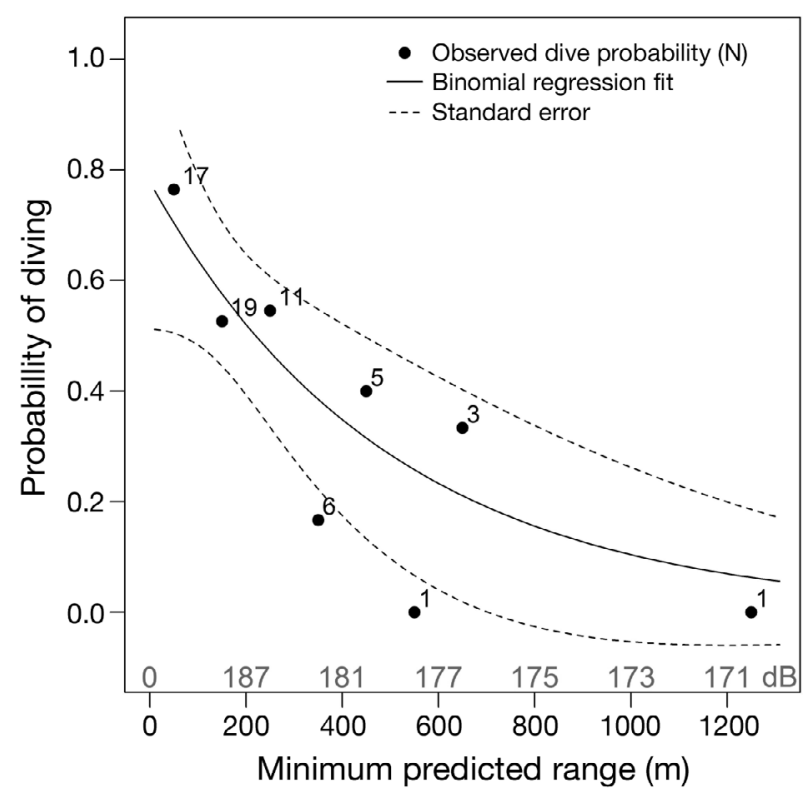

Fig. 4. Field data (in $100 \mathrm{~m}$ bins) and fitted binomial regression model for dive probability as a function of minimum range from the airgun array along the turtle trackline (log link function: model intercept $=-0.25$, parameter $=-0.0020$, $\mathrm{p}=0.020$, analysis of deviance/Chi ${ }^{2}$ test for significance of range term). The number beside each field data point indicates the number of observations (n) in that range bin. Grey numbers above $x$-axis are estimated received airgun sound levels (in $\mathrm{dB}$ re $1 \mu \mathrm{Pa}$ peak) at each range, predicted by a spherical spreading law model (see Fig. 5)

tles, 6 is a minimum estimate of the number of animals who showed this response to the airguns. The observation of even 6 such coincidences of dives and shots is inconsistent with chance overlap of independent events. The probability that 6 of 49 dives would be initiated within $0.5 \mathrm{~s}$ of an airgun shot is only 0.001 , if airguns are fired every $19.4 \mathrm{~s}$ and dive timing is unrelated to the airgun shots (binomial probability density function evaluated for the case of 49 trials, 6 successes, and probability of success $=0.5 \mathrm{~s} / 19.4 \mathrm{~s}$ ). This result indicates that the timing of the startle dives was indeed related to the airgun shots, and the coincidence of the dives and shots in time was not a chance co-occurrence of unrelated events.

A binomial regression relating turtle dive probability to minimum turtle-airgun distance along the turtles' tracklines indicated that turtles were more likely to dive when their trackline passed closer to the airgun array (Fig. 4; binomial regression with log link, intercept $=-0.25$, parameter $=-0.0020, p=0.020$ [analysis of deviance/Chi ${ }^{2}$ test for significance of range term]). As explained in 'Materials and methods', this regression analysis included only turtles never sighted at positions within $20^{\circ}$ of the ship's 


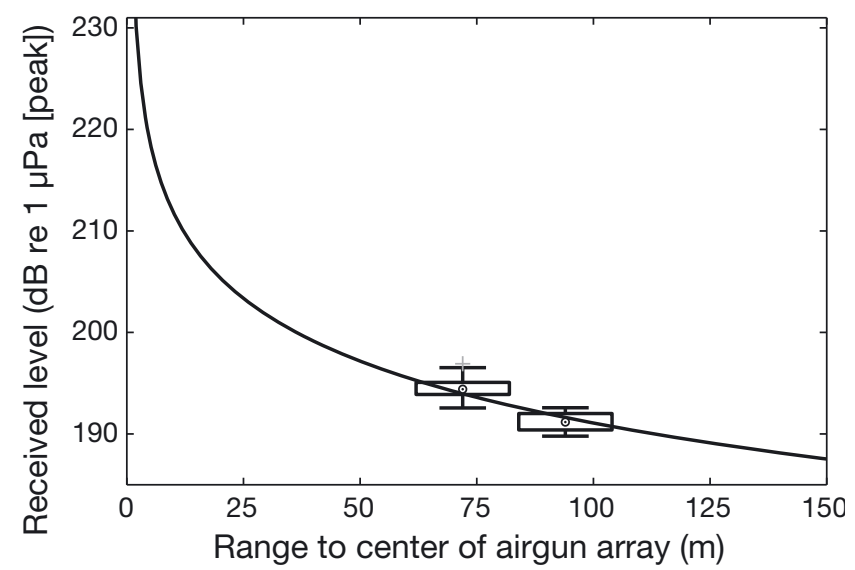

Fig. 5. Measured and modeled received levels of airgun pulses. Received levels at the hull-mounted hydrophones are shown as box-and-whiskers plots, pooling data from the 2 hydrophones at $72 \mathrm{~m}$ range. The circled dot is the median observed level; the top and bottom of the black rectangle indicate the upper and lower quartiles. The vertical lines extend to the largest and smallest observed values, up to 1.5 times the interquartile range. Values outside this range were considered outliers; the one outlier in the dataset is plotted as a grey cross. The solid black curve is the received level (RL) predicted according to RL $=\mathrm{SL}-20 \log 10(r)$, where SL is source level (252 dB re $1 \mu \mathrm{Pa}$ [peak]) and $r$ is range to the center of the airgun array

heading, to avoid biasing results by including data on turtles that might have dived in response to the ship's presence. A separate, similar analysis of the data from turtles sighted at positions within $20^{\circ}$ of the ship's heading was inconclusive and results were not statistically significant $(\mathrm{p}=0.15$, analysis of deviance/Chi ${ }^{2}$ test for significance of range term; probably due to small sample size of 10 turtles).

Received levels of airgun pulses recorded on the hull-mounted hydrophones ranged from 193 to $197 \mathrm{~dB}$ re $1 \mu \mathrm{Pa}$ (peak) at $72 \mathrm{~m}$ range and from 190 to $193 \mathrm{~dB}$ re $1 \mu \mathrm{Pa}$ (peak) at $94 \mathrm{~m}$ range (Fig. 5). The offaxis source level of the airgun array in the direction of the hull-mounted hydrophones was predicted to be $231 \mathrm{~dB}$ re $1 \mu \mathrm{Pa}$, while the off-axis source level in the direction of a turtle at the surface $130 \mathrm{~m}$ in front of the array was $233 \mathrm{~dB}$ re $1 \mu \mathrm{Pa}$. Using the off-axis source level of $231 \mathrm{~dB}$, a simple spherical spreading law was able to accurately predict the received levels at the hull-mounted hydrophones (Fig. 5). Therefore, the model was applied (using the off-axis source level of $233 \mathrm{~dB}$ ) to produce estimates of the received levels experienced by turtles observed at the sea surface (Fig. 4). According to this model, the received airgun sound level would be about $191 \mathrm{~dB}$ re $1 \mu \mathrm{Pa}$ (peak) for a turtle $130 \mathrm{~m}$ from the array (the median distance at which turtles dove).

\section{DISCUSSION}

The observations reported here document a behavioral response of loggerhead turtles Caretta caretta to airgun array sounds. The turtles interrupted basking behavior and dove in response to the sound. The observed dives occurred at relatively close ranges (median: $130 \mathrm{~m}$, maximum: $839 \mathrm{~m}$ ) and thus relatively high exposure levels (estimated to be about $191 \mathrm{~dB}$ re $1 \mu \mathrm{Pa}$ [peak] at $130 \mathrm{~m}$ and $175 \mathrm{~dB}$ at $839 \mathrm{~m}$ ). Turtle dive probability declined with increasing minimum range to the array along the turtle's trackline. This type of dive reaction could have negative fitness consequences for individual turtles if it interfered with thermoregulation, caused inhabitual energy expenditures, or otherwise excluded turtles from optimal habitat. Alterations of turtle behavior may also raise animal welfare concerns related to sound exposure, as individual quality of life could be reduced by the changes. These data on turtle responses to airguns should be considered during the development of regulations designed to protect marine animals from anthropogenic sounds.

Although thresholds for marine mammal behavioral responses to impulsive sounds like airgun pulses are still not clearly understood, they have often been observed to respond at lower received levels (110 to $180 \mathrm{~dB}$ root mean square) than did the turtles in our study (Southall et al. 2007). The lower sensitivity of turtles is not particularly surprising, because their hearing is much less acute than that of most marine mammals (DeRuiter 2010).

The modeled received levels of airgun sounds by turtles presented here should be considered rough estimates, since the spherical spreading model used to predict levels was validated using data from only 3 hydrophones, which were closely spaced. Recordings from receivers at additional ranges would be required to better resolve received level patterns and assess model accuracy, but the estimated received levels presented here should be accurate at least at distances close to the source-hydrophone ranges (72 to $94 \mathrm{~m}$ ).

An obvious criticism of our study is to point out that it lacks proper controls, since we were unable to observe turtle behavior when airguns were not firing. Because the observations were collected during a geophysical research project, turtle observers did not have control over airgun operation times, and there was simply no opportunity to collect such control data. However, the location and timing of dive responses suggest the turtles were responding to the airgun sounds, and not some other cue. Dive proba- 
bility was higher for turtles whose tracks passed closer to the airgun array. An aversive response to the presence of the ship is one possible explanation for this relationship, but our results suggest that airgun sounds played a major role. To avoid mistaking turtle dives in response to vessel presence for dives in response to the airguns, we excluded from our statistical analysis data from all turtles sighted within $20^{\circ}$ of the ship's heading, and thus likely to pass close to the ship's bow and possibly dive in response to the ship. We still found a significant relationship between dive probability and distance from the array, and other observations also support the conclusion that turtles responded to the airgun sounds. According to observer notes on turtle behavior, only 3 turtles dove in apparent response to the proximity of the ship, while 6 displayed a startle response and then dove immediately following airgun array shots, all 6 at ranges of $>100 \mathrm{~m}$ from the ship's hull. The coincidence in the timing of the sounds and the responses shows that the reactions were, indeed, related to the airgun sound exposure and were not simply a reaction to the vessel or the physical presence of the array at the surface.

Our results contrast with those of Weir (2007), who observed the behavior of 240 sea turtles of at least 3 species during airgun surveys off Angola. The careful analysis by Weir (2007) did not detect a behavioral response of the turtles to the airgun sounds: about $80 \%$ of turtles remained at the surface without being observed to dive, and no statistical analysis was done to assess the relationship between dive behavior and range to the sound source. In our study, at least $7 \%$ of turtles dove immediately after an airgun shot, when they were relatively far from the ship and seismic gear (100 m or more); in Weir's study (2007), almost all turtles that dove did so in response to the close proximity $(\sim 10 \mathrm{~m})$ of the vessel or surface floats associated with the airgun array. The discrepancy between the 2 studies suggests that turtle responses to airguns may vary by species (most turtles identified to species in Weir's study [2007] were olive Ridley turtles Lepidochelys olivacea), location, life-history stage, or behavioral state. However, it should be noted that the majority of the Angolan turtles were basking when they were first sighted, as were the turtles observed in our study. Variation in airgun source levels or exposure levels between the 2 studies might also explain some discrepancy in the results; although the reported source levels are similar in the 2 cases, Weir (2007) did not measure any received levels. Finally, analysis methodology was quite different between the 2 studies (Weir 2007 and the present analysis).
Prolonged basking behavior, particularly by aggregations of sea turtles, has been reported quite rarely, with instances in Angola and in the Mediterranean Sea (Weir 2007, M. White pers. comm.). Data from satellite-tagged turtles seem to indicate that such surface behavior could be quite common, although surface durations are rarely reported and the tag data tracks relatively few individual animals. For example, 5 juvenile loggerheads tagged in the western Mediterranean Sea spent about $35 \%$ of their time at the surface, with the smallest individual spending even more time at the surface (Cardona et al. 2005). Satellite telemetry from 2 loggerhead turtles in the central North Pacific indicated that the turtles spent $60 \%$ of daylight hours and $40 \%$ of their time overall at the surface, double the value for 2 olive Ridley turtles tagged in the same study (Polovina et al. 2004, 2003). Two female loggerheads tagged in Japan spent 13 and $22 \%$ of their time at the surface (Hatase et al. 2007). In the Gulf of Mexico, however, 4 tagged loggerhead turtles spent 90 to $95 \%$ of their time underwater, and only rarely stayed at the surface for more than even 2 to 3 min (Renaud \& Carpenter 1994).

During the present study, we were able to take advantage of a rarely witnessed phenomenon-a surface aggregation of loggerhead turtles basking in calm seas - to observe turtle responses to airgun array sounds. Based on our finding that the turtles alter their behavior in response to airguns, at least under some conditions, we recommend that turtles be considered more carefully in environmental impact statements and regulations related to airgun array operations. At present, most such documents focus on marine mammals (Castellote 2007, Weir \& Dolman 2007, Compton et al. 2008). To our knowledge, only Brazil and Canada currently stipulate that airgun operation must stop if turtles are sighted near the array (Fisheries and Oceans Canada 2005, IBAMA 2005). However, UK regulations now recommend protection for turtles in areas where they occur, United States guidelines for the Gulf of Mexico mention turtles, and measures requiring shut-down of airguns due to turtle proximity may sometimes be adopted voluntarily by airgun operators (MMS 2007, JNCC 2010). Effective at-sea mitigation of potential impacts of airguns on turtles is very challenging, since turtles are difficult to spot unless conditions are calm, and they cannot be detected by passive acoustic monitoring. Minimizing survey activity in areas important to turtles may be a more effective option, at least in places where turtle spatio-temporal distribution is known. Even though development of 
effective mitigation measures is likely to be very challenging, added consideration of turtles in noise pollution regulations is especially warranted considering the endangered or threatened status of most sea turtle populations.

Acknowledgements. The authors offer special thanks to the science party of the SPIRAL project, as well as the officers and crew of the RV 'Atalante', for their exemplary support and assistance in the field. X. Lurton, Y. Le Gall, J.-P. Regnault, E. Menut, S. Duduyer, D. Clec'h, H. Floc'h, and D. Gillespie offered helpful advice and technical assistance preparing for the cruise. M. White, L. Boura, and T. Pusser provided useful information on sea turtle biology and identification. P. Tyack, X. Lurton, and 3 anonymous reviewers provided helpful comments on earlier versions of this manuscript.

\section{LITERATURE CITED}

Bartol SM, Musick JA, Lenhardt ML (1999) Auditory evoked potentials of the loggerhead sea turtle (Caretta caretta). Copeia 1999:836-840

> Cardona L, Revelles M, Carreras C, San Félix M, Gazo M, Aguilar A (2005) Western Mediterranean immature loggerhead turtles: habitat use in spring and summer assessed through satellite tracking and aerial surveys. Mar Biol 147:583-591

> Castellote M (2007) General review of protocols and guidelines for minimizing acoustic disturbance to marine mammals from seismic surveys. J Int Wildl Law Policy 10: 273-288

Compton R, Goodwin L, Handy R, Abbott V (2008) A critical examination of worldwide guidelines for minimising the disturbance to marine mammals during seismic surveys. Mar Policy 32:255-262

de Gurjão LM, de Freitas JEP, Araújo DS (2005) Observations of marine turtles during seismic surveys off Bahia, northeastern Brazil. Mar Turtle Newsl 108:8-9

DeRuiter SL (2010) Marine animal acoustics. In: Lurton X (ed) An introduction to underwater acoustics: principles and applications (2nd edn). Praxis Publishing, Chichester, p 425-474

> DeRuiter SL, Tyack PL, Lin YT, Newhall AE, Lynch JF (2006) Modeling acoustic propagation of airgun array pulses recorded on tagged sperm whales (Physeter macrocephalus). J Acoust Soc Am 120:4100-4114

Fisheries and Oceans Canada (2005) Statement of Canadian practice with respect to the mitigation of seismic sound in the marine environment. Fisheries and Oceans Canada, Ontario. Available at: www.dfo-mpo.gc.ca/oceans/ management-gestion/integratedmanagement-gestionin tegree/seismic-sismique/statement-enonce-eng.asp (accessed 8 December 2010)

Hatase H, Omuta K, Tsukamoto K (2007) Bottom or midwater: alternative foraging behaviours in adult female loggerhead sea turtles. J Zool 273:46-55

IBAMA (Instituto Brasileiro do Meio Ambiente) (2005) Guia de monitoramento da biota marinha em atividades de asuisição de dados sìsmicos (Abril 2005). IBAMA, Ministério do Meio Ambiente, Instituto Brasileiro do Meio Ambiente e dos Recursos Naturais Renovaveis, Diretoria de Licenciamento e Qualidade Ambiental, Coordenaçâo
Geral de Licenciamento, Escritorio de Licenciamento des Atividades de Petroleo e Nuclear, Brésil

IUCN (International Union for Conservation of Nature) (2011) 2011 IUCN Red List of Threatened Species. Available at: www.iucnredlist.org/ (accessed 7 October 2011)

JNCC (Joint Nature Conservation Committee) (2010) JNCC guidelines for minimising the risk of disturbance and injury to marine mammals from seismic surveys. JNCC, Aberdeen. Available at: www.jncc.gov.uk/page-1534 (accessed 8 December 2010)

Ketten DR, Bartol SM (2005) Functional measures of sea turtle hearing: final report to the Office of Naval Research. Woods Hole Oceanographic Institution, Woods Hole, MA

Kinzey D, Gerrodette T (2001) Conversion factors for binocular reticles. Mar Mamm Sci 17:353-361

Le Gall YX, Lurton X, Llort-Pujol G, Sintes C (2010) Transducers and array processing. In: Lurton X (ed) An introduction to underwater acoustics: principles and applications (2nd edn). Praxis Publishing, Chichester, p 167-224

Lerczak JA, Hobbs RC (1998) Calculating sighting distances from angular readings during shipboard, aerial, and shore-based marine mammal surveys. Mar Mamm Sci 14:590-599

Lurton X, Leviandier L (2010) Underwater acoustic wave propagation. In: Lurton X (ed) An introduction to underwater acoustics: principles and applications (2nd edn). Praxis Publishing, Chichester, p 13-74

McCauley RD, Fewtrell J, Duncan AJ, Jenner C and others (2000) Marine seismic surveys - a study of environmental implications. APPEA J 2000:692-708

Miller PJO, Johnson MP, Madsen PT, Quero ME, Biassoni N, King R, Tyack PL (2009) At-sea experiments provide preliminary evidence that airguns affect the foraging behavior of sperm whales in the Gulf of Mexico. Deep-Sea Res I 56:1168-1181

MMS (Minerals Management Service) (2007) Notice to lessees and operators (NTL) of federal oil, gas, and sulphur leases in the outer continental shelf, Gulf of Mexico OCS Region: implementation of seismic survey mitigation measures and protected species observer program. United States Department of the Interior, MMS, Gulf of Mexico OCS Region, New Orleans, LA. Available at: www.nmfs.noaa.gov/ocs/mafac/meetings/2010_06/docs/ mms_2007_ntl.pdf (accessed 8 December 2010)

Moein Bartol S, Musick JA (2003) Sensory biology of sea turtles. In: Lutz PL, Musick JA, Wyneken J (eds) Biology of sea turtles. CRC Press, Boca Raton, FL, p 79-102

O'Hara J, Wilcox JR (1990) Avoidance responses of loggerhead turtles, Caretta caretta, to low frequency sound. Copeia 1990:564-567

Pacault A, Lurton X (2010) Sub-bottom investigation. In: Lurton X (ed) An introduction to underwater acoustics: principles and applications (2nd edn). Praxis Publishing, Chichester, p 371-424

Parente CL, Lontra JD, d Araújo ME (2006) Occurrence of sea turtles during seismic surveys in northeastern Brazil. Biota Neotropica 6 doi: 10.1590/S1676-06032006000100004

Polovina JJ, Howell E, Parker DM, Balazs GH (2003) Divedepth distribution of loggerhead (Carretta carretta) and olive ridley (Lepidochelys olivacea) sea turtles in the central North Pacific: Might deep longline sets catch fewer turtles? Fish Bull 101:189-193

Polovina JJ, Balazs GH, Howell EA, Parker DM, Seki MP, Dutton PH (2004) Forage and migration habitat of log- 
gerhead (Caretta caretta) and olive ridley (Lepidochelys olivacea) sea turtles in the central North Pacific Ocean. Fish Oceanogr 13:36-51

Renaud ML, Carpenter JA (1994) Movements and submergence patterns of loggerhead turtles (Caretta caretta) in the Gulf of Mexico determined through satellite telemetry. Bull Mar Sci 55:1-15

Ridgway SH, Wever EG, McCormick JG, Palin J, Anderson $\mathrm{JH}$ (1969) Hearing in the giant sea turtle, Chelonia mydas. Proc Natl Acad Sci USA 64:884-890

Southall BL, Bowles AE, Ellison WT, Finneran JJ and others (2007) Marine mammal noise exposure criteria: initial scientific recommendations. Aquat Mamm 33:411-521

Streeter K, Floyd S (1999) Exploring operant conditioning in a

Editorial responsibility: Jeffrey Seminoff,

La Jolla, California, USA green sea turtle. In: Kalb H, Wibbels T (eds) Proceedings of the 19th annual symposium on sea turtle conservation and biology. NOAA Tech Memo NMFS-SEFSC-443 p 8-10. US Dept of Commerce, NOAA, NMFS, Miami, FL Available at: www.sefsc.noaa.gov/turtles/TM_443_Kalb_ Wibbels_19.pdf (accessed 27 February 2009)

Weir CR (2007) Observations of marine turtles in relation to seismic airgun sound off Angola. Mar Turtle Newsl 116: $17-20$

> Weir CR, Dolman SJ (2007) Comparative review of the regional marine mammal mitigation guidelines implemented during industrial seismic surveys, and guidance towards a worldwide standard. J Int Wildl Law Policy 10: $1-27$

Submitted: February 10, 2011; Accepted: October 18, 2011 Proofs received from author(s): December 29, 2011 